\title{
Palm-coein classification of abnormal uterine bleeding and clinicohistopathological correlation
}

\author{
Vimal H. Vasava*, Bhavesh B. Airao, Milan R. Shingala
}

Department of Obstetrics and Gynecology, C. U. Shah Medical College and Hospital, Surendranagar, Gujarat, India

Received: 07 February 2021

Revised: 13 March 2021

Accepted: 15 March 2021

*Correspondence:

Dr. Vimal H. Vasava,

E-mail: milanshingala08@gmail.com

Copyright: ( ) the author(s), publisher and licensee Medip Academy. This is an open-access article distributed under the terms of the Creative Commons Attribution Non-Commercial License, which permits unrestricted non-commercial use, distribution, and reproduction in any medium, provided the original work is properly cited.

\begin{abstract}
Background: The aim was to categorize women with AUB as per the PALM-COEIN classification system as this is a step towards cause based diagnosis and focused management of patients. The acronym PALM-COEIN comes from arranging basic categories of the classification system. The PALM group comprises the structural entities, which can be measured visually or by using imaging techniques and histopathology. The COEIN group comprises the nonorganic types which cannot be defined by imaging or histopathology.

Methods: The study comprised 350 women of reproductive age with AUB for minimum 3 month time span. It describes and observes AUB in amount, interval and frequency for women attending out-patient Gynaecology department of C. U. Shah Medical College and Hospital, Surendranagar (Gujrat) over a period of 1year from November 17 to October 18. They were assessed on the basis of structured history, physical examination, local pelvis examination, investigations, USG findings and endometrial histopathological report. Cause of AUB was determined and treatment was given to the patient as appropriated by categorization done in agreement with the PALM-COEIN classification.

Results: The most prevalent cause of AUB was ovulatory dysfunction ( $\mathrm{n}=99,28.2 \%)$. Next common cause was leiomyoma $(n=90,25.7 \%)$, followed by endometrial causes $(n=52,14.5 \%)$, adenomyosis $(n=30$, 8.5\%) not yet classified $(n=32,9.7 \%)$, malignancy and hyperplasia $(n=28,8.1 \%)$, polyp $(n=9,2.5 \%)$, iatrogenic $(n=7,2.2 \%)$ and coagulopathy $(\mathrm{n}=1,0.3 \%)$.

Conclusions: The PALM-COEIN classification helps to practically as certain because of AUB, and there by effectively adopt the correct treatment for AUB patients.
\end{abstract}

Keywords: Abnormal uterine bleeding, AUB, Adenomyosis, Classification system, Malignancy, Ovulation, Polyp leiomyoma

\section{INTRODUCTION}

AUB is a significant clinical entity, affecting $14-25 \%$ women of reproductive age. ${ }^{1,2}$ It is a common and debilitating condition with high direct and indirect cost. Since long, word such as menorrhagia, metrorrhagia and dysfunctional uterine bleeding have been used to describe AUB which are confusing, controversial and poorly defined. FIGO menstrual disorders working group proposed abandoning such terms for menstrual disturbances as such differing term make it extremely difficult to interpret the patient's pathology or bleeding condition. $^{3}$ The consensus established that AUB is an appropriate term because it includes different types of menstrual bleeding and at the same time implies that it should exclude bleeding from the cervix or the lower genital tract. It also proposed that AUB in non-pregnant women can be Acute or Chronic. ${ }^{3}$ Acute AUB requires 
prompt intervening to prevent further blood loss. Chronic AUB is bleeding from the uterine corpus persistent in the last 6 months and can be abnormal in terms of amount, interval or frequency. ${ }^{4}$

In recent years, concern regarding use of terminologies and definition around symptoms of AUB has increased. Simpler terms with clear meaning were needed that can be easily understood by the medical community. Therefore an improved classification system has been named by International Federation of Gynaecology and Obstetrics (FIGO) in 2011, which is called PALMCOEIN. ${ }^{6}$ PALM holds for the pathologies related to the uterine structural anomalies (polyp, adenomyosis, leiomyoma, malignancy and endometrial hyperplasia). COEIN holds for the pathologies unrelated with uterine structural anomalies (ovulatory dysfunction, coagulopathy, endometrial, iatrogenic, and unclassified). The PALM-COEIN system structurally evaluates AUB in women which helps to understand and identify causes and contributors to the symptoms. ${ }^{7}$

\section{METHODS}

The present study is descriptive observational conducted at Obstetrics and Gynecology department of C.U Shah Medical College and Hospital, Surendranagar (Gujrat) over a period of 1year from November 17 to October 18 . In this study, we have enrolled 350 nongravid women of age group 15 to55 years with irregular, unpredictable, abnormal volume, excessive or scanty duration or abnormal frequency of menses and inter-menstrual bleeding for a minimum of 3 months duration attending Obstetrics and Gynecology outdoors.

Data were analysed by SPSS version 16 and descriptive statistics were presented as frequencies, percentages and bar charts. Z-test was applied to know the significance of the correlation.

P: Polyps were categorized either absent or present and diagnosed by history, per speculum exam, ultrasound and/or histopathological exam.

A: Adenomyosis was identified based on medical history and ultrasound (asymmetrical myometrial appearance accompanied by a large uterus), and diagnosed by MRI and even on hysterectomy specimen. ${ }^{16}$

L: Leiomyoma was identified and diagnosed by ultrasound. This study includes only primary classification of leiomyoma, i.e., it reflect sonly the presence or absence of leiomyoma regardless of location, number and size.

M: If malignant or premalignant lesion was suspected, endometrial biopsy was performed for histopathology.

C: Coagulopathy was identified by patterned medical history, and diagnosed by coagulation test.
O: Ovulatory dysfunction included AUB cases of unpredictable time period and inconsistent amount of flow. It can be due to anovulation or disturbed ovulation. Endocrinopathies, polycystic ovarian syndrome, hypothyroidism, hyperprolactinemia and weight changes are included in this group.

E: Endometrial causes include those AUB women who have predictable and cyclic bleeding typical of ovulatory cycles. The cause might been do metrial origin. It is a diagnosis of exclusion

I: Iatrogenic group includes intrauterine contraceptives, gonadal steroids, anticonvulsant, antibiotics, antidepressants and anticoagulant drugs.

$\mathrm{N}$ : Not yet classified. It is inevitable that there will be pathologies that are either are or poorly defined that do not easily fit with incategories described earlier.

\section{RESULTS}

A total 6,300 women attending the gynaecology OPD during the study duration, $70(18.6 \%)$ women put up with AUB of these women, 350 were studied in this report. All these cases were placed in then in categories of PALMCOEIN classification. Maximum patients, $47.7 \%$, were in the age group of $40-50$ years and $37.4 \%$ were in the 30 40 years age group (Table 1). Majority of patients, $37.4 \%$, complained of heavy bleeding as chief complaint. $27 \%$ had irregular heavy bleeding and $22 \%$ had frequent bleeding (Table 2).

Table 1: Age distribution of study population.

\begin{tabular}{|lll|}
\hline Age group(year) & Total number & Percentage \\
\hline $\mathbf{2 0}$ & 5 & 1.40 \\
\hline $\mathbf{2 0 - 3 0}$ & 15 & 4.20 \\
\hline $\mathbf{3 0 - 4 0}$ & 131 & 37.40 \\
\hline $\mathbf{4 0 - 5 0}$ & 167 & 47.70 \\
\hline $\mathbf{> 5 0}$ & 32 & 9.10 \\
\hline
\end{tabular}

Table 2: Distribution of study population based on presented complaints.

\begin{tabular}{|lll|}
\hline Symptoms (complaints) & $\begin{array}{l}\text { Total } \\
\text { number }\end{array}$ & Percentage \\
\hline Heavy menstrual bleeding & 131 & 37.4 \\
\hline Irrregular heavy bleeding & 95 & 27.0 \\
\hline Intermenstrual bleeding & 7 & 02.0 \\
\hline Frequent bleeding & 77 & 22.0 \\
\hline Post menopausal bleeding & 28 & 08.0 \\
\hline $\begin{array}{l}\text { Infrequent or scanty } \\
\text { bleeding }\end{array}$ & 12 & 03.4 \\
\hline
\end{tabular}

As per the PALM-COEIN classification, ovulatory dysfunction $(28.2 \%)$ was the most prevalent cause of AUB in our study. Simple ovarian cysts and PCOS were common sonographic findings. Hormone imbalance was 
common on endometrial histopathological report. Thyroid imbalance was also noted. Next common category was Leiomyoma AUB-L ( $n=90,25.7 \%)$, followed by Endometrial AUB-E causes ( $n=52,14.5 \%)$, adenomyosis AUB-A ( $\mathrm{n}=30,8.5 \%)$, Malignancy AUB-M $(\mathrm{n}=28,8.1 \%)$, Not classified AUB-N ( $\mathrm{n}=32,9.7 \%)$, Polyp AUB-P (n=9, 2.5\%), iatrogenic AUB-I $(n=7,2.2 \%)$ and coagulopathy AUB- C $(n=1,0.3 \%)$ (Table 3$)$.

This study focuses to categorize the patient of AUB as per the PALM-COEIN classification and is similar to studies by presented with AUB were in age group 40- 50 years $(47.7 \%)$ and $30-40$ years $(37.4 \%)$. Of the presented complaints, heavy menstrual bleeding (37.4\%) was the most common, followed by irregular heavy bleeding $(27 \%)$ and frequent bleeding $(22 \%)$. It was also noted that infrequent and scanty bleeding was more common in obese and PCOS women.
Table 3: Distribution of study population according to PALMCOEIN classification (total 350 patients).

\begin{tabular}{|llll|}
\hline Caues & & $\begin{array}{l}\text { Total } \\
\text { number }\end{array}$ & $\%$ \\
\hline & Polyp (AUB-P) & 9 & 02.5 \\
\hline Structural & Adenomyosis (AUB-A) & 30 & 08.5 \\
\hline & Leiomyoma (AUB-L) & 90 & 25.7 \\
\hline \multirow{2}{*}{\begin{tabular}{l} 
Non $\begin{array}{l}\text { Structural } \\
\text { Malignancy (AUB-M) }\end{array}$ \\
\cline { 2 - 4 }
\end{tabular}} & $\begin{array}{l}\text { Coagulopathy (AUB-C) } \\
\text { Ovulatory dysfunction }\end{array}$ & 1 & 08.1 \\
\hline & AUB-O) & 00.3 \\
\cline { 2 - 4 } & Endometrial (AUB-E) & 52 & 28.2 \\
\cline { 2 - 4 } & Itrogenic (AUB-I) & 7 & 02.2 \\
\cline { 2 - 4 } & $\begin{array}{l}\text { Not yet classified } \\
\text { (AUB-N) }\end{array}$ & 32 & 09.7 \\
\hline
\end{tabular}

Table 4: Comparison of distribution of causes.

\begin{tabular}{|lllllll|}
\hline Causes & Category & Present study & Gouri et al & Goel et al & $\begin{array}{l}\text { Qureshi and } \\
\text { Yusuf }\end{array}$ & Ratnani et al \\
\hline Polyp & $\mathrm{P}$ & $09(02.5 \%)$ & $06(02.0 \%)$ & $08(02.7 \%)$ & $30(03.0 \%)$ & $40(13.3 \%)$ \\
\hline Adenomyosis & $\mathrm{A}$ & $30(08.5 \%$ & $38(12.7 \%)$ & $28(09.3 \%)$ & $150(15 \%)$ & $60(20.0 \%)$ \\
\hline Leiomyoma & $\mathrm{L}$ & $90(25.7 \%)$ & $74(24.7 \%)$ & $68(22.7 \%)$ & $250(25 \%)$ & $105(35 \%)$ \\
\hline $\begin{array}{l}\text { Malignancy or } \\
\text { hyperplasia }\end{array}$ & $\mathrm{M}$ & $28(08.1 \%)$ & $15(05.0 \%)$ & $08(02.7 \%)$ & $66(06.7 \%)$ & $65(21.6 \%)$ \\
\hline Coagulopathy & $\mathrm{C}$ & $01(00.3 \%)$ & $09(03.0 \%)$ & $03(01.0 \%)$ & $03(03.0 \%)$ & $02(00.6 \%)$ \\
\hline $\begin{array}{l}\text { Ovulatory } \\
\text { dysfunction }\end{array}$ & $\mathrm{O}$ & $99(28.2 \%)$ & $81(27.0 \%)$ & $85(28.3 \%)$ & $236(24 \%)$ & $60(20.0 \%)$ \\
\hline Endometrial & $\mathrm{E}$ & $52(14.5 \%)$ & $27(09.0 \%)$ & $62(20.7 \%)$ & $48(05.0 \%)$ & $12(04.0 \%)$ \\
\hline Iatrogenic & $\mathrm{I}$ & $07(02.2 \%)$ & $24(08.0 \%)$ & $13(04.3 \%)$ & $53(06.0 \%)$ & $03(01.0 \%)$ \\
\hline Not yet classified & $\mathrm{N}$ & $32(09.7 \%)$ & $19(6.3 \%)$ & $25(08.3 \%)$ & $155(15 \%)$ & $03(01.0 \%)$ \\
\hline
\end{tabular}

This study encapsulates the ease of use and implementation of this classification system. Moreover, treatment of pathology was easier where the cause of AUB was determined. In present study, we could understand the major causes of AUB grouped into structural and non-structural cause. In both groups, management plans were different, hence management was more focused and tailored to specific cause. The major disadvantage was in cases of patients who belonged to AUB-N category because treatment is vague in this category in absence of diagnosis. Also, COEIN part of classification needs further improvement through elaborate research.

\section{DISCUSSION}

The aim to conduct this study was to test the efficiency and practicality of PALM-COEIN classification system in clinical practice in determining the cause of disease and treatment modality for patient showing AUB at out patient department. The new FIGO classification was developed to clear longstanding apprehension regarding terminologies and definitions related to AUB. These terms referred to symptoms or diagnosis, were not clear, and on the contrary these terms created confusion in treatment of AUB cases. This study focuses to categorize the patient of AUB as per the PALM-COEIN classification and is similar to studies by Khrouf et al; Munro et al; Madha et al; Bahamondes et al. ${ }^{6-10}$ With this, necessary investigations can be easily done and better management of specific causes can be planned.

In present study, most of the patients presented with AUB were in age group 40-50 years $(47.7 \%)$ and $30-40$ years $(37.4 \%)$. Of the presented complaints, heavy menstrual bleeding $(37.4 \%)$ was the most common, followed by irregular heavy bleeding $(27 \%)$ and frequent bleeding (22\%). It was also noted that in frequent and scanty bleeding was more common in obese and PCOS women. ${ }^{11}$ According to study done by Gouri et al in May'16, category which had the most patients was ovulatory dysfunction (27\%), followed by leiomyoma $(24.7 \%) .{ }^{11}$ In study done by Goel et al, ovulatory dysfunction was found to be the most common cause of AUB $(28.3 \%)$ followed by leiomyoma $(22.7 \%){ }^{12}$ In present study also, ovulatory dysfunction was found to be 
the most common cause of AUB (28.2\%) (Table4). PCOS, hormonal dysfunction, thyroid dysfunction, simple ovarian cyst were included in this category. This study encapsulates the ease of use and implementation of this classification system. Moreover, treatment of pathology was easier where the cause of AUB was determined. In present study, we could understand the major causes of AUB grouped into structural and nonstructural cause. In both groups, management plans were different, hence management was more focused and tailored to specific cause. The major disadvantage was in cases of patients who belonged to AUB-N category because treatment is vague in this category in absence of diagnosis .Also ,COEIN part of classification needs further improvement through elaborate research.

\section{Limitation}

Patients giving negative consent for hysterectomy and patients denies for histopathological examination.

\section{CONCLUSION}

To identify the exact cause is essential to successfully treat patients with AUB. The PALM- COEIN classification helps to practically as certain the cause of AUB, and there by effectively adopt and plan for focused treatment of patients. It is also important to regularly improvise and improve this classification system in line with changes and improvements in medical science and technology. It also needs to adapt to the available options as per demographics.

Funding: No funding sources

Conflict of interest: None declared

Ethical approval: The study was approved by the Institutional Ethics Committee

\section{REFERENCES}

1. Fraser IS, Langham S. Health related quality of life and economic burde no fabnormal uterine bleeding. Expert Rev Obstet Gynaecol. 2009;4:179-89.

2. Shapley M, Jordan K, Croft PR. An epidemiological survey of symptoms of menstrual loss in the community. Br J Gen Pract. 2004;54:359-63.

3. Munro MG, Critchley HOD, Fraser IS. The flexible FIGO classification concept for underlying causes of abnormal uterine bleeding. Semin Reprod Med. 2011;29:391-9.

4. Munro MG, Broder M, Critchley HOD, Matteson K, Haththotu R, Fraser IS. An international response to questions about terminologies, investigation, and management of abnormal uterine bleeding: use of an electronic audience response system. Semin Reprod Med. 2011;29:436-45.

5. Fraser IS, Critchley HOD, Broder M, Munro MG. The FIGO recommendation on terminologies and definitions for normal and abnormal uterine bleeding. Semin Reprod Med. 2011;29:383-90.

6. Munro MG, Critchley HOD, Broder M, Fraser IS. FIGO working group on menstrual disorders. FIGO classification system (PALM-COEIN) for causes of abnormal uterine bleeding in non-gravid women of reproductive age. Gynaecol Obstet. 2011;113(1):313.

7. Munro MG, Critchley HOD, Fraser IS. The FIGO systems for nomenclature and classification of causes of abnormal uterine bleeding in there productive years:who needs them? Am J Obstet Gynaecol. 2012;207(4):259-65.

8. Khrouf M, Terras K. Diagnosis and management of formerly called dysfunctional uterine bleeding" according to PALM-COEINFIGO classification and the new guidelines. Obstet Gynaecol India. 2014;64:388-93.

9. Madhra M, Fraser IS, Munro MG, Critchley HOD. Abnormal uterine bleeding: advantages of formal classification to patients, clinicians and researchers Acta Obstet Gynaecol Scand. 2014;93:619-25.

10. Bahamondes L, Ali M. Recent advances inmanaging and understanding menstrual disorders. Prime Rep. 2015;7:33.

11. Gouri SRS, Lakshmi PV, Rani NG, Kumar NA. Categorization of the causes of AUB according to PALM-COEIN classification. Int J Scientific Study. 2016;4(2):97-9.

12. Goel P, Rathore SB. PALM-COEIN FIGO classification for diagnosis of abnormal uterine bleeding. Sch J App Med Sci. 2016;4(8A):2771-3.

13. Qureshi FU, Yusuf AW. Distribution of causes of abnormal uterine bleeding using the new FIGO classification system. J Pak Med Assoc. 2013;63:973-5.

14. Ratnani R, Meena N. Aclinico-pathological analysis of causes of abnormal uterine bleeding according to PALM- COEIN classification. JMSCR. 2017;5(09):28196-200.

15. Sharma JB, Yadav M. New ground breaking International Federation of Gynaecology and Obstetrics's classification of abnormal uterine bleeding. JM Life Health. 2013;4(1):42-5.

16. Demirps HD, Ulusoy M, Cailk E, Solmaz U, Gevenal T. Assessment of patients with abnormal uterine bleeding in the reproductive period according to PALM-COEIN classification system. Scient Open Access Journal. 2016;9:45-9.

Cite this article as: Vasava $\mathrm{VH}$, Airao BB, Shingala MR Palm-coein classification of abnormal uterine bleeding and clinicohistopathological correlation. Int J Reprod Contracept Obstet Gynecol 2021;10:158790. 